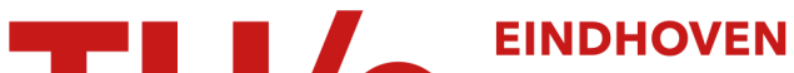 \\ UNIVERSITY OF \\ TECHNOLOGY
}

\section{Speciality products based on commodity polymers}

Citation for published version (APA):

Lemstra, P. J., \& Kirschbaum, R. (1985). Speciality products based on commodity polymers. Polymer, 26(9), 1372-1384. https://doi.org/10.1016/0032-3861(85)90315-5

DOI:

10.1016/0032-3861(85)90315-5

Document status and date:

Published: 01/01/1985

\section{Document Version:}

Publisher's PDF, also known as Version of Record (includes final page, issue and volume numbers)

\section{Please check the document version of this publication:}

- A submitted manuscript is the version of the article upon submission and before peer-review. There can be important differences between the submitted version and the official published version of record. People interested in the research are advised to contact the author for the final version of the publication, or visit the $\mathrm{DOI}$ to the publisher's website.

- The final author version and the galley proof are versions of the publication after peer review.

- The final published version features the final layout of the paper including the volume, issue and page numbers.

Link to publication

\section{General rights}

Copyright and moral rights for the publications made accessible in the public portal are retained by the authors and/or other copyright owners and it is a condition of accessing publications that users recognise and abide by the legal requirements associated with these rights.

- Users may download and print one copy of any publication from the public portal for the purpose of private study or research.

- You may not further distribute the material or use it for any profit-making activity or commercial gain

- You may freely distribute the URL identifying the publication in the public portal.

If the publication is distributed under the terms of Article $25 f a$ of the Dutch Copyright Act, indicated by the "Taverne" license above, please follow below link for the End User Agreement:

www.tue.nl/taverne

Take down policy

If you believe that this document breaches copyright please contact us at:

openaccess@tue.nl

providing details and we will investigate your claim. 


\title{
Speciality products based on commodity polymers
}

\author{
Piet J. Lemstra and Rob Kirschbaum \\ DSM, Research and Patents, Geleen, The Netherlands \\ (Received 21 December 1984)
}

\begin{abstract}
Synthetic polymers constitute an established class of materials. The distinction often made between the massproduced commodity polymers and speciality polymers is less clearly defined, since with novel preparation techniques bulk polymers are now increasingly used in speciality applications. Such new applications of commodity polymers often compete with the classical inorganic materials: metals and glasses. In this respect synthetic polymers often suffer from inferior performance with respect to strength/stiffness, barrier properties etc. These deficiencies are not necessarily intrinsically related to commodity polymers, as will be demonstrated with some examples: high-modulus/high-strength polyethylene fibres and barrier films based on polypropylene.
\end{abstract}

(Keywords: high-strength/high-modulus PE fibres; gel spinning; barrier blends)

\section{INTRODUCTION}

Synthetic polymers, in the past often synonymous with cheap substitutes (plastics), have a well-established position today in the spectrum of available materials, as is illustrated by their production volume of slightly over $50 \times 10^{6}$ tonnes in $1983^{1}$. A distinction is often made between speciality and commodity polymers. The concept of speciality (high-performance) vs. commodity (bulk) is used in - but not restricted to - the chemical industry to differentiate chemicals, plastics and also fabricated products in terms of market-size/price/number of producers/performance criteria ${ }^{2}$.

The four major mass-produced polymers: polyethylene (PE), poly(vinylchloride) (PVC), polystyrene (PS) and polypropylene (PP), constitute over $70 \%$ of the total polymer production volume ${ }^{3}$ and are, by all criteria, commodities. Polymers like ABS, the polyamides nylon 6 and 66 etc., which were considered to be specialities in the past, have lost this status and are often referred to as engineering plastics, to distinguish their intermediate position between specialities and commodities in terms of pricing/performance/application, see Figure l.

Newly-developed synthetic polymers are inevitably specialities at the beginning of their life-cycle. Numerous specialities have been developed or are under development, exhibiting for instance high-melting temperatures, increased high-impact resistance, high-strength/highmodulus, electrical conductivity etc. ${ }^{4}$ (see Table I). Despite the effort that has been made to develop a large variety of specialties, their market share is still limited to a few per cent of the total synthetic polymer production.

It is obvious that any differentiation between specialities, engineering and commodity pol.ymers is of a dynamic nature. A speciality polymer, combining a few excellent characteristics, has the potential to acquire an engineering status. A polymer like ABS is sometimes referred to as an engineering, sometimes as a commodity polymer, which indicates its changing status. Given the foregoing considerations, commodity polymers seem, at first sight, the bottom end of the market with material characteristics making them only suitable to substitute glass, metal and paper in low-performance products. These generalizations, however, are far from reality. For example, polyethylene (the largest bulk-produced polymer) is in fact a generic name for a versatile class of materials which have in common the recurring monomer ethylene as the base unit, but differ with respect to chain length, branch content and chain regularity, resulting in a large variety of properties and applications. In fact some $\mathrm{PE}$ grades can be considered to be specialities in the sense that they are designed for a specific purpose or application.

In the search for new areas of application, commodity

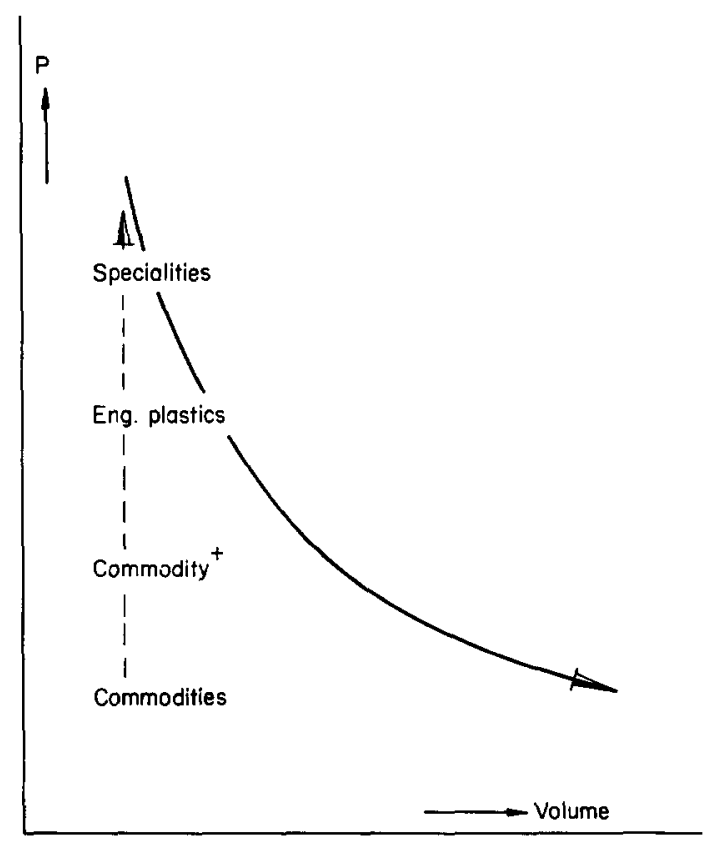

Figure 1 Price-property-performance vs. volume for synthetic polymers 
Table 1 Commodities, engineering and specialities (some examples)

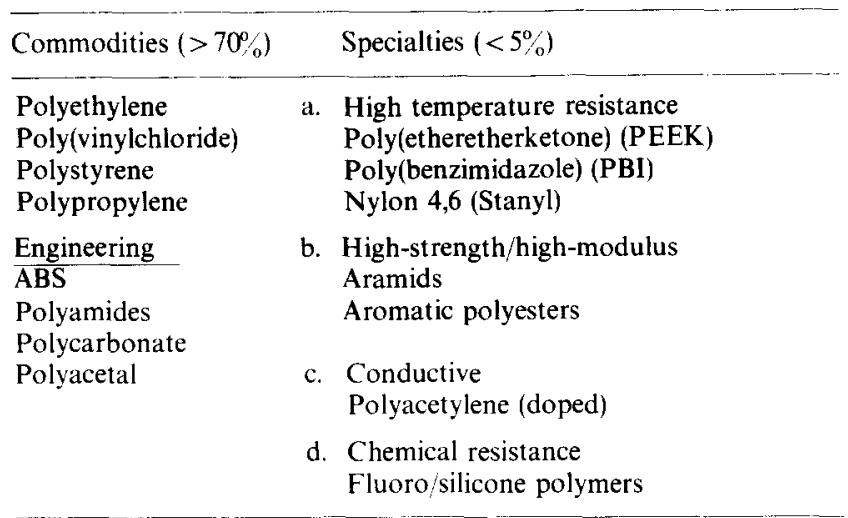

Table 2 Examples of commodity ${ }^{+}$grades

\begin{tabular}{lll} 
& Description & Improved property \\
\hline PP & $\begin{array}{l}\text { Narrow molecular weight } \\
\text { distribution } \\
\text { Block-copolymers }\end{array}$ & Control of rheology \\
PE & $\begin{array}{l}\text { UHM } \\
\text { PE-PE }- \text { Imes }\end{array}$ & $\begin{array}{l}\text { Abrasion resistance } \\
\text { Low melt viscosity } \\
\text { LLDPE }\end{array}$ \\
PVC & $\begin{array}{l}\text { High molecular weight } \\
\text { Graft copolymers (EVA/VC) } \\
\text { Chlorinated PVC (C-PVC) }\end{array}$ & $\begin{array}{l}\text { Viscoelasticity } \\
\text { Impact resistance } \\
\text { Heat distortion temperature }\end{array}$ \\
PS & Graft copolymers (HIPS) & Impact resistance \\
\hline
\end{tabular}

polymers are modified to meet the requirements/specifications as imposed by, for instance, the automotive and electronic industries. Mechanical, thermal, optical and other properties are improved by optimizing the polymerization conditions, molecular weight tailoring, copolymerization, blending and additives. Typical examples are shown in Table 2 . These grades are sometimes referred to as commodity-plus $\left(\mathrm{C}^{+}\right)$types ${ }^{5}$. Usually no spectacular changes in properties are obtained or aimed at, the main target being to widen the application areas.

For many high-performance applications these commodity-plus types, but also the engineering plastics, cannot compete with the classical inorganic materials, glass and metals, notably with respect to mechanical strength, stiffness, barrier properties and continuous use temperature. To bridge the gap in properties there are, in principle, two possible routes. One was discussed above, i.e., the development of specialities based on new chemistry and focused usually on one property, for instance strength/modulus, impact, melting point. Another possible route, although restricted to certain characteristics, is to exploit to an absolute maximum the intrinsic properties of existing commodity polymers, in fact a step which goes far beyond the commodity-plus approach (as indicated by the dashed arrow in Figure 1). We will discuss two examples in which, by simple physical means of blending and (ultra)drawing, properties are attained which are comparable to or competitive with those of glasses and metals, but realized on the basis of commodity polymers like PE and PP. They therefore, have the additional advantages with respect to density and impact resistance, for example. We will first discuss the progress made in a time span of about 15 years towards production of high-strength and extremely stiff structures based on intrinsic flexible macromolecule such as PE. In the second part it will be shown how processing of intractable systems such as incompatible blends can be optimized to obtain products which combine mechanical performance with barrier properties.

\section{ULTRA-DRAWING OF POLYETHYLENE}

\section{Polyethylene; its intrinsic possibilities}

The strength and stiffness of standard polyethylene (isotropic) is comparatively low, usually $<0.05$ and $2 \mathrm{GPa}^{*}$, respectively. For many applications, higher values are not necessary or even undesirable, for example in flexible/tough films. The polyethylene chain, a linear array of covalently bonded C-atoms is potentially very stiff and strong. Mark ${ }^{6}$ estimated the strength of a $\mathrm{C}-\mathrm{C}$ bond to be $\approx 25 \mathrm{GPa}$. A more recent calculation gave the following results for a linear polyethylene chain: breaking stress $19 \mathrm{GPa}$ at a strain at break of $33 \%$ and a corresponding modulus of $300 \mathrm{GPa}^{7}$. These calculations however are based on loading an infinite chain to the limit (rupture of $\mathrm{C}-\mathrm{C}$ bonds). Although it is possible to polymerize linear polyethylenes possessing molecular weights $\left(M_{w}\right)$ of up to several dozens of millions (in fact these grades are produced commercially, the so-called UHMW-PE types), the maximum length of these high molecular weight chains in the extended chain conformation is still limited to $<100 \mu \mathrm{m}$. The ultimate strength of macroscopic polyethylene systems are therefore more dependent on interchain contact and slippage of chains under stress than on loading individual chains to break, even more so since specific interactions like hydrogen bonding are absent and only relatively weak van der Waals forces operate between chains.

Due to the highly anisotropic character of linear macromolecules one focuses automatically on exploiting maximum strength/stiffness in one direction, i.e., fibrous systems. More than 50 years ago, Carothers formulated a few criteria for obtaining high-strength fibres, such as the necessity of long molecules, oriented and ordered in an array with the chain axis parallel to the fibre axis ${ }^{8}$. Based on these considerations, polyethylene is an excellent candidate for obtaining high strength and stiffness values. It is possible to polymerize nearly linear and very long molecules, $M_{\mathrm{w}}>10^{6} \mathrm{~kg} \mathrm{kmol}^{-1}$. Since no pendant groups are present tacticity/stereoregularity is not a complicating factor leading to a reduction in crystallizability (atactic) or helical conformations in the crystalline state (isotactic) with an intrinsically lower value for the modulus (for example isotactic polypropylene). The absence of pendant groups also implies that a polyethylene chain has one of the smallest cross sectional areas amongst all synthetic macromolecules. Consequently the number of loadbearing elements per fibre cross section is relatively high, provided the chains are fully extended in the fibre direction.

Schaefgen has estimated the strength of a nearly perfectly aligned and crystalline $P E$ structure to be $\approx 3.7 \mathrm{GPa}$, based on Zimmerman's theory of creep failure $^{9}$. Although this estimated value is substantially lower than the $19 \mathrm{GPa}$ mentioned before (calculated on the basis of chain breakage) it is still impressive in comparison with

\footnotetext{
* $\quad 1 \mathrm{GPa}=10^{9} \mathrm{~N} \mathrm{~m}^{-2}=(1 \mathrm{~N} /$ Tex for PE $)$
} 
current values of high-performance fibres such as the aramids and carbon, especially when the specific strength is taken into account (strength per unit weight) which is typically $<2 \mathrm{GPa}$ for the latter class of materials.

In conclusion, the linear polyethylene chain possesses some characteristics which makes it a suitable candidate for obtaining high-strength/high-modulus structures. The major problem which has to be solved is to meet the essential requirement: chain extension/alignment, taking into account that the PE chain is flexible and the extended chain conformation is highly improbable. This is in contrast with for instance the aromatic polyamides and polyesters where polymer chemists designed intrinsically stiff macromolecules which are prone to orient during flow.

Numerous studies have been devoted to maximum orientation in polyethylene systems. Various processes have been developed or are under development, mainly based on deformation in the solid phase and/or employing solvents to obtain a suitable precursor for ultradrawing. We will summarize solid-state deformation processes for a better understanding of the gelspinning process developed at DSM.

\section{Solid-state deformation processes}

Andrews and Ward ${ }^{10}$ started drawing studies of linear polyethylene some 15 years ago and investigated the influence of molecular weight and draw ratio on properties of drawn structures. Via melt-spinning, isotropic monofilaments were obtained which were post-drawn after solidification. They found that the axial Young's modulus of the drawn filaments increased monotonically with increasing draw ratio, and they obtained moduli up to $\approx 20 \mathrm{GPa}^{*}$.

In later studies, Ward et al. ${ }^{11}$ systematically investigated the dependence of post-drawing behaviour on processing variables. It was found that crystallization conditions affected the drawability in the sense that slow cooling from the melt promotes the effective drawability of the solid. By optimizing the spinning and solidification conditions, moduli could be obtained of up to $70 \mathrm{GPa}$ by post-drawing the extruded/crystallized filaments in a temperature range close to, but below, the end-melting temperature. Since the density of PE is nearly unity these PE structures possess specific moduli beyond those of glass and steel, if compared on the basis of stiffness/weight (specific modulus).

Ward and coworkers found ${ }^{12}$ that the beneficial effect of slow cooling from the melt was restricted to the lower molecular weight range for polyethylene. Moreover the drawability of the solidified polyethylene decreased with increasing molecular weight. The maximum attainable draw ratio decreases monotonically with increasing molecular weight, approaching a limiting value of $<10$ at $M_{\mathrm{w}}$ 's above $10^{6} \mathrm{~kg} \mathrm{kmol}^{-1}$, sometimes referred to as the natural draw ratio.

With increasing molecular weight, polyethylene (as well as other polymeric systems) increasingly resists deformation. This applies not only to deformation in the solid state in tensile drawing but also to the melt, where the viscosity increases rapidly with $M_{\mathrm{w}}$. Therefore meltspinning and subsequent post-drawing of the solid phase

\footnotetext{
* In this paper, all quoted experimental values for modulus and strength refer to room temperature measurements
}

has a limitation with respect to the choice of polyethylenes. Typically, polyethylenes with moelcular weights $>\approx 5 \times 10^{5}\left(M_{\mathrm{u}}\right)$ are difficult to spin from the melt due to melt fracture and if proper spinning conditions were available, post drawing would be less effective since the maximum draw ratio is limited.

These limits with respect to molecular weight are reflected in the ultimate values for the tensile strengths, $\approx 1 \mathrm{GPa}$. As stated before for high tensile strengths, long and perfectly-oriented molecules are a pre-requisite. At Monsanto USA, Wu and Black optimized the meltspinning process on a well-tuned spinning line and obtained maximum values for strength and stiffness of 1.4 and $70 \mathrm{GPa}$, respectively ${ }^{13}$.

The advantage of the Ward process is its simplicity and therefore, in principle, a low cost price of the fibres/tapes based on a cheap commodity polymer PE but offering properties which could be attractive for many applications ${ }^{14}$.

Deformation in the solid state is not restricted to tensile drawing of spun/extruded filaments/tapes (nor to polyethylene itself). Using high pressures one can force solid polyethylene (in the form of preformed billets) through a die, for instance via hydrostatic extrusion etc. ${ }^{15,16}$. Basically these deformation techniques/modes involve the same molecular processes and therefore the same limitations with respect to molecular weight apply if meltcrystallized PE is used as the precursor for solid state deformation. Of course in solid state/hydrostatic extrusion processes one avoids the melt-processing step but to obtain high-modulus structures the solid polyethylene precursor has to be deformed to high EDR (extrusion draw ratios), similar to high draw ratios in tensile drawing and the process becomes increasingly difficult with increasing molecular weight.

\section{Limits in drawability/natural draw ratio}

The decrease in drawability/draw ratio and EDR values with increasing molecular weights is an experimentally well-verified fact and the concept of a natural draw ratio is not uncommon for drawing polymeric systems. For instance in melt-spinning of nylons, filaments are post-drawn to increase the mechanical properties of the yarns. The maximum attainable draw ratio is limited to $\approx 5-6$, depending on spinning conditions (draw down). The natural draw ratio for tensile drawing is however not predicted by or based on any current model of polymer morphology/crystallization.

For example, polyethylene chains in the melt and in concentrated solutions are ideal in the sense that $\left\langle R^{2}\right\rangle$, the mean square end-to-end distance, is linear in the molecular weight $M$. Although it is not decided yet how the individual chains should behave upon cooling from the melt ${ }^{17}$, they certainly form crystallites. Depending on crystallization conditions and molecular weight, the conformation of the PE-chain in the solid will retain (some of) its random coil character from the melt or approach the folded-chain conformation as found in PE lamellar crystals obtained by slow cooling of dilute solutions. In discussing the drawing behaviour of PE in the solid phase one has to focus on the initial situation, the conformation of the chain in the (isotropic) solid and the ultimate goal: the fully extended chain in the fibre. The actual situation should lie in between two extremes: (a) the conformation of the chain in the solid is similar to the situation in the 

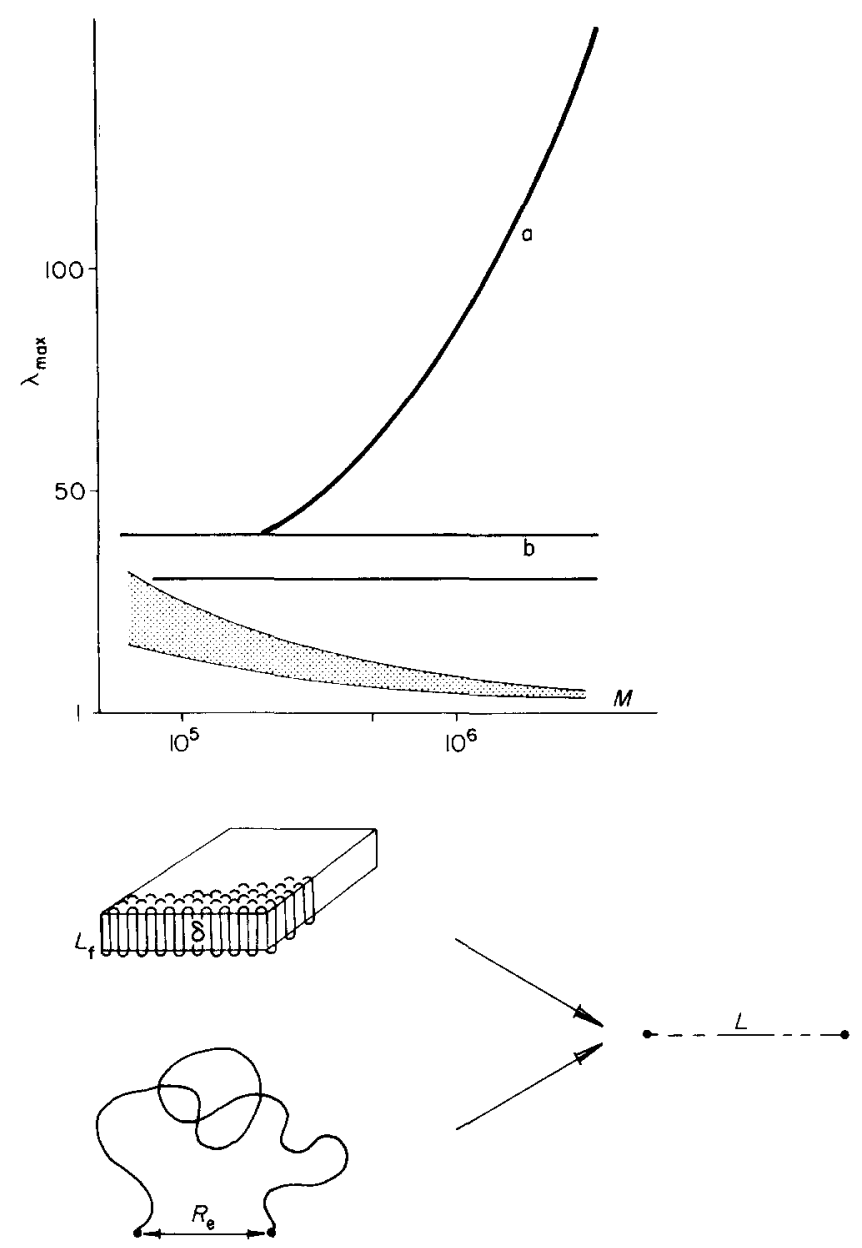

Figure 2 Draw ratio $i_{\text {mix }}$ as function of molecular weight for PE in solid-state drawing, showing difference between: (a) random coil; and (b) folded-chain conformation in comparison with actual drawability (dotted area)

melt; and (b) the chain conformation is regularly folded. If (a) holds, the maximum (molecular) draw ratio $\lambda_{\text {max }}$ is given by the ratio of the extended chain length $L$ and the end-to-end distance $R e$ in the isotropic solid. In case of PE, $L=0.83 n l$ ( $n$ is the number of $-\mathrm{CH}_{2}-$ units and $l$ the $\mathrm{C}-\mathrm{C}$ bond length) ${ }^{18}$ and $\operatorname{Re}=\left\langle R^{2}\right\rangle^{0.5}$ where $\langle R\rangle^{2}=\mathrm{Cn} l^{2}$ ( $C=$ characteristic ratio). Taking $C=6.7$ as an average value $^{18.19}$, the maximum draw ratio as a function of molecular weight $M$ is given by:

$$
\lambda_{\text {max }}=0.086(M)^{0.5}
$$

For regularly (adjacent-reentry) folded chain crystals, (case (b)), the draw ratio is given by the ratio of fold length $\left(L_{\mathrm{f}}\right)$ and the chain diameter $(\delta)$, which in case of polyethylene amounts to draw ratios between $\approx 30$ and 40 . Figure 2 shows the two extreme cases (a) and (b) and the actual situation with respect to draw ratio as a function of $M$, as encountered in drawing polyethylenes. The large discrepancy between actual values and the calculated ones implies that other factors controlling drawability operate in solid-state deformation/drawing of polyethylene.

\section{Orientation in solution/shish-kebabs}

The dimensions of flexible polymers like polyethylene in solution depend on the choice of solvent, temperature and concentration. For dilute solutions in good solvents the coil expands due to excluded volume effects and in the limiting case of approaching zero concentration $\left\langle R^{2}\right\rangle \sim M^{1.2}$, rather than linear in $M$ (see ref. 20). Dilute solutions with isolated coiled macromolecules are not compatible with any continuous spinning process in which continuity is provided by chain overlap, but, nevertheless, studies on stretching/orienting in the limiting case of dilute solutions are of interest to understand which factors govern and limit chain extension.

From hydrodynamic theories simple conditions can be obtained concerning stretching of individual macromolecules. In general to stretch the chain the hydrodynamic driving force should exceed the entropic restoring force towards the random coil conformation. The type of flow is an important choice in view of the aim of fully stretching out a macromolecule (see the discussion in ref. 21). Elongational flows are in particular suitable for extending the chain. The following conditions hold for chain extension $^{22}$ :

$$
\dot{\varepsilon} . \tau \gg 1 ; \dot{\varepsilon} . \Delta t \gg 1
$$

In equation (2), $\dot{\varepsilon}$ is the rate of strain in the flow direction and $\tau$ the characteristic relaxation time and $\Delta t$ the time during which the macromolecule is exposed to the flow field. The relaxation time is dependent on the molecular weight. Mackley and Keller $^{23}$ concluded from their experiments on polyethylene that $\tau \sim M^{1.75}$ which implies that, in actual systems, where the molecular weight distribution is very broad, only fractional chain extension is obtained. They calculated for the system polyethylene in xylene that at a rate of strain of $1000 \mathrm{~s}^{-1}$ (which is extremely high for any spinning system) only molecules with molar masses $>2 \times 10^{6}$ will become fully stretched out. This reflects the intrinsic problem of orienting a flexible macromolecule like polyethylene as an individual unit.

Chain extension in slightly super-cooled solutions of polyethylene could be made permanent by nucleation and growth of aligned macromolecules into fibrous structures. Slightly supercooled solutions are a prerequisite to avoid spontaneous nucleation and growth of folded chain crystals, the usual mode of crystallization occurring at lower crystallization temperatures.

At DSM Central Research it was found that fibrous PE crystals are formed in a Couette apparatus if the inner rotor exceeded a critical rotation rate ${ }^{24}$. It was found that the critical rotation rate coincided with the onset of Taylor vortices in the dilute and supercooled PE solutions, which are known to contain elongational components. When high-molecular weight PE was used the correspondence between fibrous crystal growth and Taylor vortices was less clear, which in retrospect can be attributed to a less clear understanding of entanglementcoupling at the time (see the section on gelspinning/ultradrawing).

The morphology of the stirring-induced fibres has been thoroughly investigated and the crystals have become known as 'shish-kebab'. In the fibrous material a central core is present consisting of more or less extended PEmolecules (shish) and on the core lamellar crystals are present (kebab). This type of morphology is easy to understand in terms of the foregoing discussion about orientation and relaxation of chains in solution. Since the high molecular weight part of a particular PE sample is more prone to orient during stirring, a backbone will develop on which during cooling the unoriented mo- 


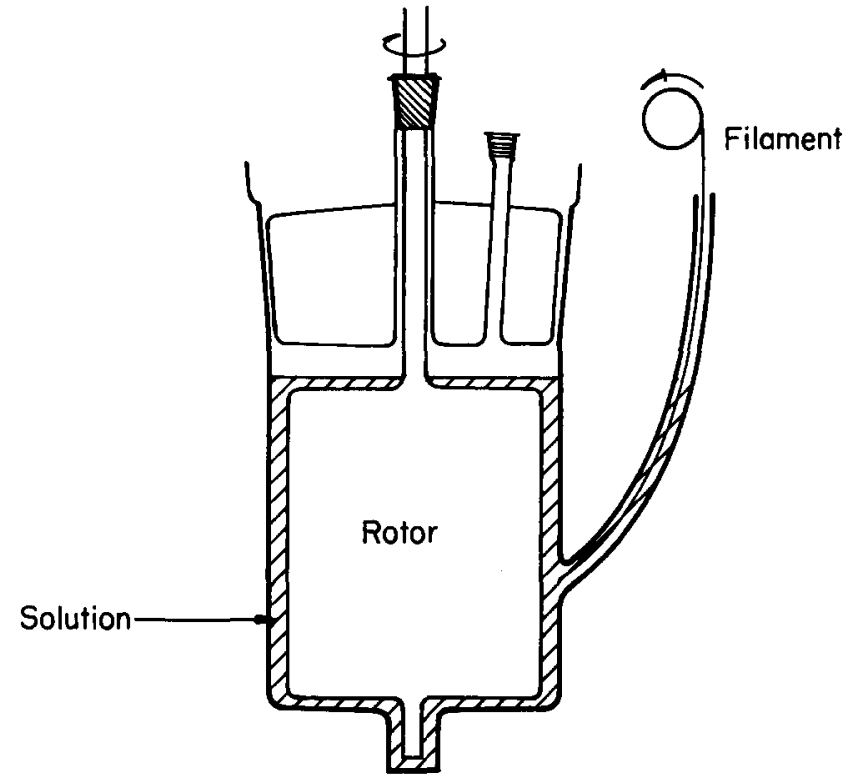

Figure 3 Schematic representation of surface-growth technique

lecules will crystallize (nucleate) either as a free molecule or entangled with the backbone. For a detailed discussion about the formation and structure of shish-kebabs, see refs 22,25 and 26 . The structure of a shish-kebab type fibre is far from the ideal situation of an arrangement of parallel chains, due to the presence of lamellar overgrowth. The maximum moduli obtained by stirring at the highest possible solution temperatures, to reduce the amount of lamellar overgrowth, amounted to $\approx 25 \mathrm{GPa}^{27}$. This value is not impressive in view of the moduli obtained via solid-state deformation in tensile drawing.

The early work on stirred-induced crystallization was followed by various methods of fibre-growing methods like free growth ${ }^{28}$ etc and culminated in the so-called surface growth technique. This surface-growth technique was a significant breakthrough since polyethylene fibres could be grown from a rotating surface in a dilute solution of high molecular weight polyethylene with excellent mechanical properties, viz. a tensile modulus of over $100 \mathrm{GPa}$ and a strength $>3 \mathrm{GPa}$. This technique was studied in detail by Zwijnenburg/Meihuizen/Pennings (University of Groningen) ${ }^{29}$ and by Barham and Keller (University of Bristol) $^{25,26}$. Figure 3 shows an experimental set-up (taken from ref. 30) of the surface growth method. A seed fibre, immersed in solution between two concentric cylinders in which the inner cylinder rotates, is withdrawn from the inner rotating cylinder and upon withdrawal fibres are pulled from the surface. This technique is continuous in the sense that by replenishing the solution between the cylinders fibre growth is continuous and fibres with the aforementioned excellent mechanical properties are obtained, due to improved crystal perfection at these high growth temperatures ${ }^{26}$.

The surface growth technique clearly demonstrates that from very high molecular weight $P E$, typically $>10^{6} \mathrm{~kg}$ $\mathrm{kmol}^{-1}$ (UHMW-PE grades), oriented structures could be obtained possessing excellent mechanical properties with respect to stiffness and strength, in fact matching the predicted values by Schaefgen mentioned before ${ }^{9}$. The surface growth method is the experimental realization of ultra-high strength/high-modulus PE fibres. Many efforts were taken to understand the factors governing the speed of fibre production, to increase this speed and to develop alternative/optimized surface growth techniques, see for example ref. 31. But growth rates were limited to $<1 \mathrm{~m} \mathrm{~min}^{-1}$, which is far too low for any technological and commercial fibre spinning process.

\section{GELSPINNING/ULTRA-DRAWING}

In the late 1970s it was found at DSM Central Research that solution-spun UHMW-PE could be ultra-drawn to high-strength/high modulus fibres ${ }^{32,33}$.

Figure 4 shows schematically the elements of this process, now often referred to as PE-gelspinning. A solution of UHMW-PE, $M_{\mathrm{w}}$ typically $>10^{6}$, is spun through an orifice into a quench bath, for example water, whereupon solidification takes place. The solidified, gellike filaments possess sufficient mechanical strength to be transported via a roller system into an oven in which drawing is performed at elevated temperatures. During drawing solvent is expelled and evaporates and the stretched filaments can be wound up continuously on bobbins. If conditions for spinning and drawing are optimized with respect to concentration, molecular weight, drawing temperature and draw ratios, filaments are obtained with short-term mechanical properties (strength/modulus) equal to or better than those obtained with the surface growth technique, viz. strength values of $\approx 3$ $4 \mathrm{GPa}$ and moduli of $>100 \mathrm{GPa}$, whereas the long-term properties (creep resistance) are much better ${ }^{34,35}$.

At first glance this gelspinning process looks rather similar to standard wet-spinning processes. In view of the aforementioned difficulties in processing and drawing high molecular weight polyethylenes, the use of excess solvent seems rather obvious. Solvent will lower the viscosity and results in spinnable solutions of UHMW$P E$ and plasticizes the system during drawing. Plastization is not uncommon in processing/drawing of rather intractable polymeric materials, for example PVC and poly(vinyl alcohol) and in case of spinning/quenching into water the solvent (decalin, xylene etc) will remain in the gel-like filaments and therefore aids in aligning the longchain molecules in the hot-drawing step.

The striking feature of the gelspinning process however is that removal of solvent from the as-spun filaments prior to drawing, for example via extraction, only slightly affects the effective drawability ${ }^{36,37}$. Figure 5 clearly demonstrates the difference in drawability between: (a) melt-crystallized/compression-moulded UHMW-PE and

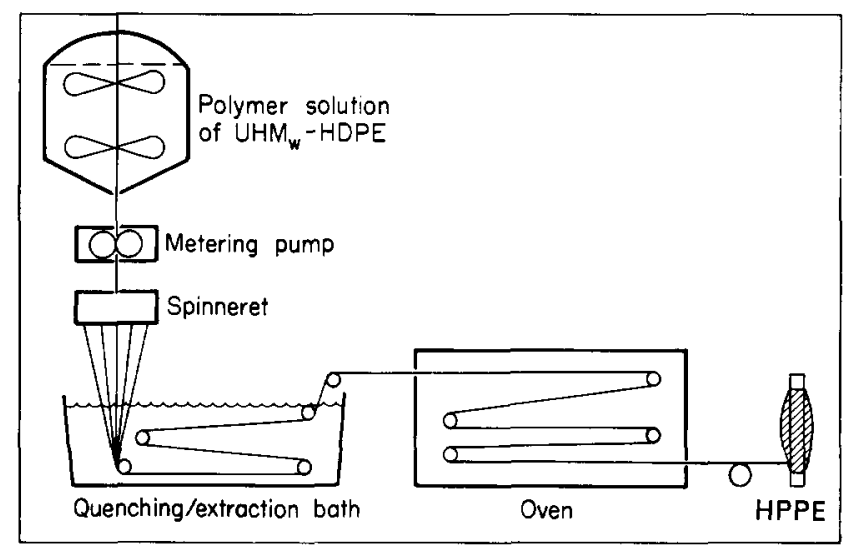

Figure 4 Schematic representation of gel spinning process 


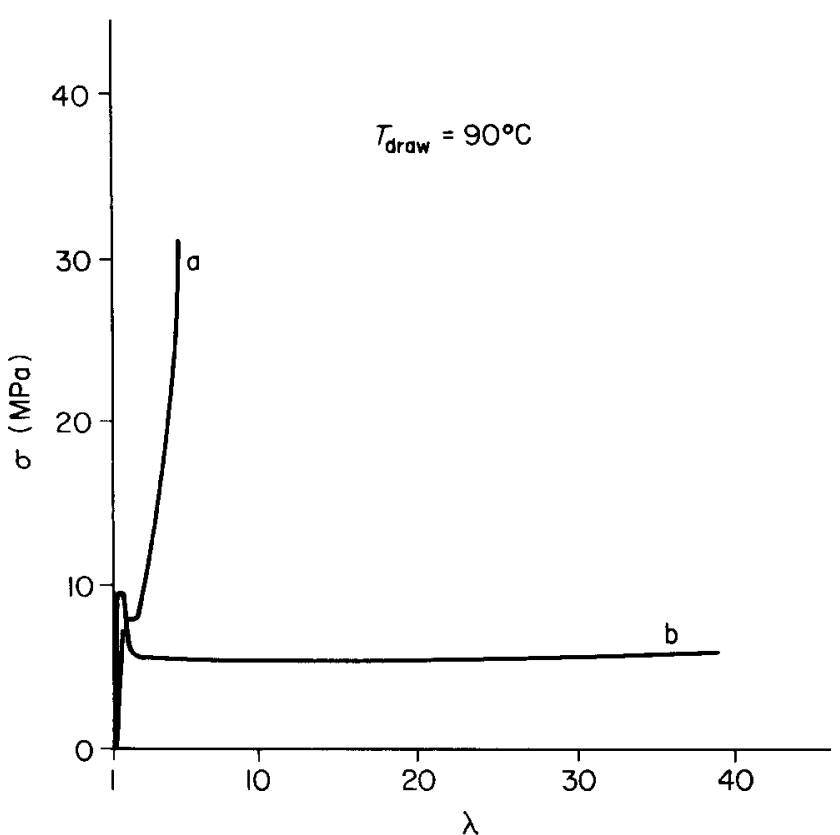

Figure 5 Nominal stress $\sigma\left(F / A_{0}\right)$ vs. draw ratio $\lambda\left(l / l_{0}\right)$ of Hostalen Gur 412 , recorded at $90^{\circ} \mathrm{C}$ at constant cross-head speed of $100 \mathrm{~mm} \mathrm{~min}^{-1}:$ (a) melt-crystallized; (b) solution-spun/extracted

(b) solution-spun/quenched and extracted UHMW-PE (in both cases the same starting material Hostalen Gur412 was used). Care was taken to remove residual solvent completely from the as-spun filaments and no detectable changes occurred during spinning with respect to the molecular weight distribution. Therefore, the large difference in drawability as depicted in Figure 5 should be related to some spinning-induced characteristic intermolecular topology/morphology which is favourable for ultra-drawing. Via spinning from semi-dilute solutions it is possible to obtain UHMW-PE structures which possess a large drawability in the solid state as expected from these long-chain molecules (see Figure 2) in contrast to melt-crystallized but chemically identical samples.

Drawing, both in melt-spinning (Ward et al.) and in the gelspinning process, is performed in a temperature range close to but below the melting temperature (or dissolution temperature in case of wet gelfilaments) and above the socalled alpha-relaxation temperature, which is $70^{\circ}-80^{\circ} \mathrm{C}$ for solid polyethylene. In this temperature range, polyethylene is still a crystalline material and therefore the arguments discussed before concerning chain conformation, random coil vs. folded-chains, still hold. Spinning from solution removes the 'constraints' which limit the drawability in melt-crystallized polyethylene, to such an extent that superdrawing is made possible. The role of the solvent is to remove the 'constraints' but once the structure is formed the solvent can be removed without losing the effective drawability, provided that redissolving and melting is prevented.

\section{Mechanism of gelspinning/ultradrawing}

Various models have been proposed to account for the strongly enhanced drawability of solution-spun fibres, notably the effect of porosity on drawability. Porosity is induced in the as-spun filaments upon extraction and the enhanced drawability has been explained in terms of excess intermolecular free volume aiding deformation ${ }^{38}$. However the porosity induced via extraction is of a macroscopic kind and not related to intermolecular free volume as shown by experiments demonstrating similar drawing characteristics for from solution-spun UHMWPE structures in which porosity was promoted or prevented, respectively ${ }^{39}$. Based on systematic investigations of the effect of initial polymer concentration in solution and the subsequent post-drawing characteristics, Smith et al. ${ }^{40}$ proposed a simple model to explain ultra-drawing of UHMW-PE. In dissolving the high molecular weight polyethylene, the number of contacts between chains decreases proportionally to the degree of dilution ${ }^{20}$. In the limiting case of dilute solutions $\left(\phi<\phi^{*}\right)$ chains are separated and consequently completely disentangled. Spinning of these dilute solutions would result in a powdery precipitate in the quench bath since no coherence between individual crystals is provided for. If spinning is performed from semi-dilute solution, in which chains overlap and are entangled to a certain extent, a coherent filament will be obtained in which the coherence is provided through frozen-in loops/trapped entanglements. In case of hypothetical melt-spinning of UHMW$\mathrm{PE}$ the situation in the melt with respect to entanglement density is retained to a large extent in the solid/quenched filaments since the high melt-viscosity is prohibitive to extensive chainfolding (and consequently disentangling).

Figure 6 schematically depicts the various possibilities and Figure 7 shows the morphology of as-spun filaments revealing the lamellar organization. In the model it is assumed that trapped entanglements act as semi-permanent crosslinks on the time scale of the drawing experiment, the more so since relaxation times in the semi-solid state are comparatively long. In case of melt-crystallized UHMW-PE, the high entanglement density per chain is prohibitive to ultra-drawing, in fact compressionmoulded/sintered UHMW-PE is well-known for its excellent resistance to deformation (notably its abrasionresistance). In the limiting case of isolated single crystals no in-line spinning/drawing is possible.

Spinning from semi-dilute solutions provides an optimum with respect to the morphology and entanglement density as shown by the dependence of the draw ratios on the initial polymer concentration in solution, see reference 40. This model is simple and combines well-known facts from polymer rheology and morphology. Statton ${ }^{41}$ reported some 15 years ago that PE single crystal mats showed remarkable extensibility provided that annealing was performed prior to drawing experiments to induce sufficient coherence between the crystals in the mats. Spinning from semi-dilute solutions automatically provides this coherence between individual lamellar crystals through trapped entanglements as visualized in this model.

At first sight the crystal structure and perfection seems to be less important than trapped entanglements, in the model for controlling drawability of polyethylene. This view is substantiated by recent experiments ${ }^{42}$ which show that the drawability of solution-crystallized UHMW-PE increased with decreasing supercooling during the crystallization process. This phenomenon was explained in terms of additional disentangling which occurs if crystallization conditions are selected which promote regular chain-folding/reeling-in and the generated PE structures show an enhanced drawability despite the fact that the crystallinity increases by more than $50 \%$. Additional disentangling as a consequence of chain-folded crystalli- 
Crystallized from:

(a) Melt

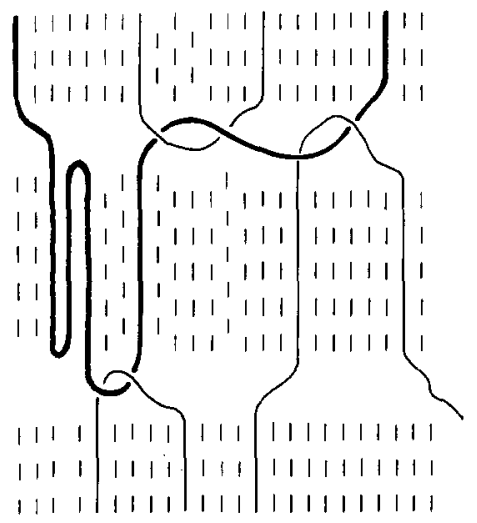

(b) Solution, $\phi>\phi^{*}$

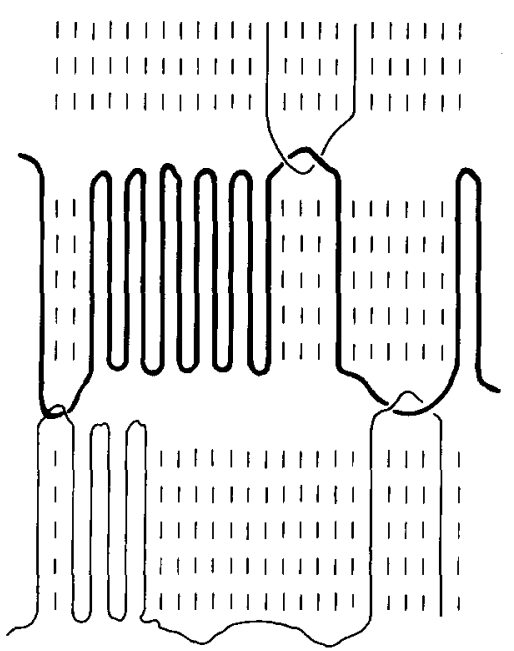

(c) Solution, $\phi<\phi^{*}$
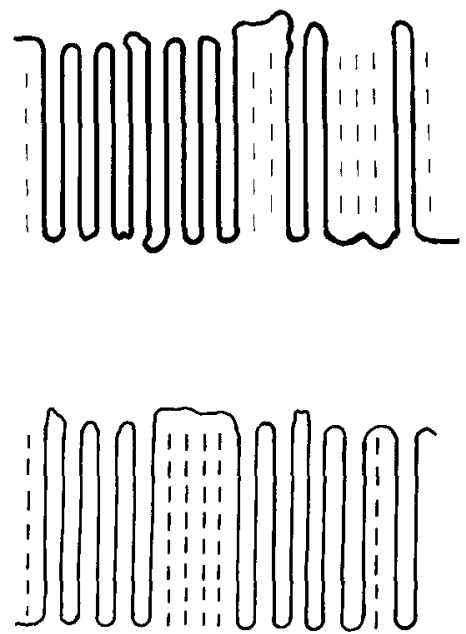

Figure 6 Chain topology in crystallized UHMW-PE showing polymer chain (bold curve) wuth entangled neighbours (light curve) and non-entangled neighbours (dashed curve): (a) crystallized from the melt; (b) crystallized from semi-dilute solutions; and (c) crystallized from dilute solutions

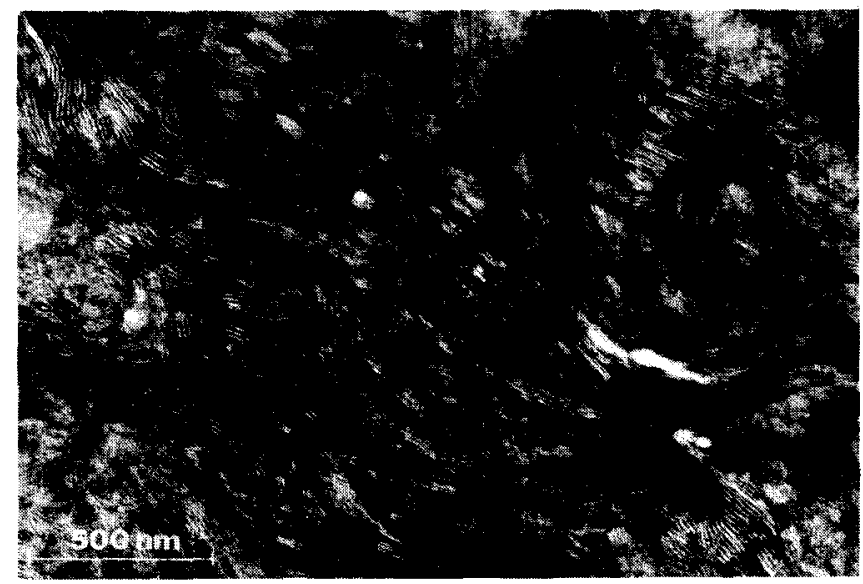

Figure 7 Electron micrograph revealing lamellar organization in asspun fibres. Courtesy of Dr J. Martinez-Salazar, C.S.I.C., Madrid

zation is not necessarily restricted to solution-crystallized UHMW-PE but could explain equally well the enhanced drawability of melt-crystallized PE upon slow cooling from the melt as found by Capaccio and Ward ${ }^{11,40}$.

The concept of a loose entanglement network structure as the ideal precursor for ultra-drawing polyethylene explains many phenomena (at least qualitatively) as discussed above, the influence of initial polymer concentration in solution on the maximum draw ratio of asspun filaments and the effect of slow cooling in promoting drawability. In retrospect a similar model has been used to explain the phenomenon of surface growth in terms of a loose entanglement network on the rotor surface ${ }^{25,26}$. During deformation it is assumed that the crystallites when present (as in gelspinning) do not resist deformation because they are ductile under the experimental conditions chosen for drawing.

\section{Stability of disentangled polyethylene}

The fact that crystals do not resist deformation does not imply that their presence can be ignored. The crystallites preserve the solution memory and prevent re-entangling

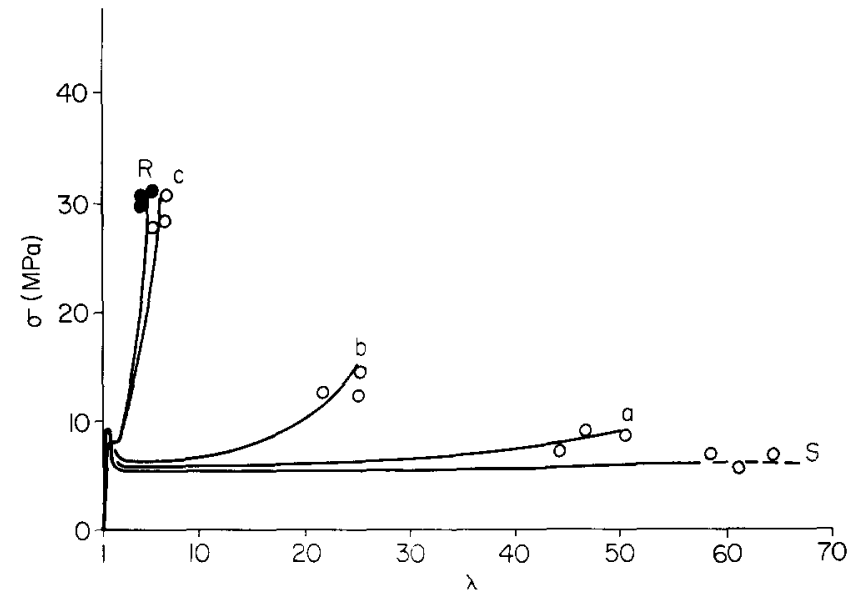

Figure 8 Nominal stress-strain curves of UHMW-PE (Hostalen Gur412) recorded at $90^{\circ} \mathrm{C}$ at constant cross-head speed of $100 \mathrm{~mm} \mathrm{~min}^{-1}$ : $\mathrm{S}=$ solution-crystallized $; \mathbf{R}=$ melt-crystallized (reference); (a), (b) and (c) are re-crystallized samples obtained by heating $S$ above melting temperature for various periods of time and followed by quenching to room temperature. Heating time, $142^{\circ} \mathrm{C}$ for (a), 10; (b), 20; and (c), $30 \mathrm{~s}$

processes. If a solution-spun/cast PE structure is heated above the melting temperature re-entangling is expected to take place. Figure 8 shows the fast decay in drawability of solution-spun UHMW-PE in the solid state after heating to and recrystallizing from the melt. Heating for $1 \mathrm{~min}$ in the melt, in this particular case at $142^{\circ} \mathrm{C}$ (compare melting temperature: $135^{\circ} \mathrm{C}$ ), is sufficient to completely destroy the solution memory, and the drawability of the molten and subsequently quenched-recrystallized sample is indistinguishable from a straight compression-moulded sample of identical chemical composition. According to the entanglement concept, this result relates to the reformation of entanglements in the molten state to such an extent that, upon re-crystallization, a solid structure is generated as shown in Figure $6 a$, i.e., comparable to crystallization from a highly entangled melt. The surprising fact is the short time scale involved for the reentangling process $(\approx 1 \mathrm{~min})$ in view of literature data 
Table 3 Mean diffusion distance

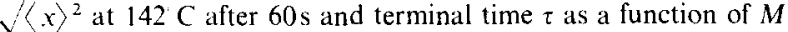

\begin{tabular}{lrcc}
\hline$M$ & $\sqrt{\langle x\rangle^{2}}(\mathrm{~nm})$ & $R_{\mathrm{g}}(\mathrm{nm})$ & $\tau(\mathrm{s})$ \\
\hline $10^{5}$ & 710 & 14 & 0.14 \\
$5 \times 10^{5}$ & 140 & 30 & 16 \\
$10^{6}$ & 70 & 43 & 132 \\
$1.5 \times 10^{6}$ & 47 & 53 & 451
\end{tabular}

which indicate that for restoring an 'equilibrium entanglement' network much longer times are needed ${ }^{43,44}$. In fact differences in melt properties, as inferred from rheological and spectroscopic measurement, can persist for many hours even at $200^{\circ} \mathrm{C}$ for $\mathrm{PE}$ samples with different processing and/or crystallization histories ${ }^{45}$. These long relaxation times have been recorded for standard molecular weight samples, whereas in our case ultra-high molecular weights $\left(M_{w}>10^{6}\right)$ are involved and consequently even longer relaxation times are expected.

An estimation of re-entangling rates can be made on the basis of recent self-diffusion measurements in polyethylene melts. De Gennes ${ }^{46,47}$ predicted the translational diffusion coefficient to scale as $D \cong M^{-2}$. Klein and Briscoe ${ }^{48}$ verified this dependence experimentally and moreover determined the prefactor and activation energy:

$$
\begin{gathered}
D=\left(26 \times 10^{-6}\right) M^{-2} \mathrm{~m}^{2} \mathrm{~s}^{-2}\left(\text { at } 176^{\circ} \mathrm{C}\right) \\
E_{\mathrm{acl}}=29.3 \times 10^{3} \mathrm{~J} \mathrm{~mol}^{-1}
\end{gathered}
$$

From equations (3) and (4), $D$ can be converted to $142^{\circ} \mathrm{C}$, the temperature for this particular experiment $\left(D=14 \times 10^{-6} M^{-2} \mathrm{~m}^{2} \mathrm{~s}^{-1}\right)$. The mean square distance (self-diffusion) in a time interval $\Delta t$ is given by $\Delta x^{2}=6 D \Delta t$. In Table 3, the mean diffusion distance is calculated and compared with the radius of gyration $R_{\mathrm{g}}$ (data taken from ref. 19) as a function of $M$ at $142^{\circ} \mathrm{C}$. The results show that even for high-molar masses the coil diffuses over a distance nearly equal to its own radius of gyration. Since linear polyethylenes are polydisperse, in the case of Hostalen Gur-412: $M_{\mathrm{w}}=1.5 \times 10^{6}$ and $M_{\mathrm{n}}=2 \times 10^{5}$, we could conclude that a major volume fraction of the macromolecules in the sample is re-entangled and that the degree of coil overlap is sufficient (after heating for $\approx 1 \mathrm{~min}$ in the melt) to obtain upon quenchingrecrystallization a solid structure whose drawing behaviour is indistinguishable from a straight melt crystallized sample (obtained in the usual way of compressionmoulding of reactor powder at $\approx 200^{\circ} \mathrm{C}$ ). The fast decay in drawaility as shown in Figure 8 is therefore not directly in conflict with the concept of trapped entanglements controlling drawability of solid polyethylene, of course within the framework of the reptation concept and diffusion data.

However at present we do not wish to apply this model

* In fact the literature data ${ }^{43.44}$ discussed above are far more difficult to understand in terms of reformation of entanglements or restoring an entanglement network structure in the melt. This was recently discussed $^{50}$ in terms of tight knots related to long time memory effects for times $\gg$ the terminal time $\tau$. The terminal time $\tau$ (disengagement time or reptation time $\left.\right|^{51}$ is given by $\tau=R^{2} / D$ and is also presented in Table 3 . For standard molecular weight polyethylenes (linear grades), no long memory times are predicted, nor complete re-entangling for higher molar masses. to other situations than those encountered in gelspinning and related phenomena such as surface-growth processes $^{25.26}$. Under experimental conditions such as recrystallization from the melt other factors are involved like multiple nucleation which could prevent the formation of regular chain-folded crystals. In the other extreme case of crystallization from very dilute solutions, to promote the formation of single crystals, the formation of trapped entanglements, tie molecules, or in general connectivity between crystals becomes less likely. However, as shown by Porter et al. ${ }^{49}$ solid-state extrusion of UHMW-PE single crystals provides sufficient coherence between the individual single crystals to obtain superdrawable extrudates and it is rather difficult to envisage entanglement formation during the extrusion process.

In conclusion it can be said that many factors are involved in drawing polyethylene and in the case of gelspinning an optimum is provided for with respect to crystal structure and connectedness to make in-line spinning/drawing possible. The connectedness is visualized in a model of trapped entanglements to explain phenomena such as dependence of drawability on initial polymer concentration, in case of gelspinning

\section{Properties of UHMW-PE gelspun fibres}

No extensive data are available as yet concerning the properties of gelspun fibres based on UHMW-PE, although recently numerous patents were applied for, notably by TOYOBO, DSM and Allied Chemicals. Some salient features of HP-PE (high-performance polyethylene fibres) are shown in Figures 9 and 10 . Due to high extension-to-break in combination with the high modulus, HP-PE structures can absorb a large amount of energy to break, as demonstrated in Table 4. In fact this can be utilized in fabrics and composite structures where

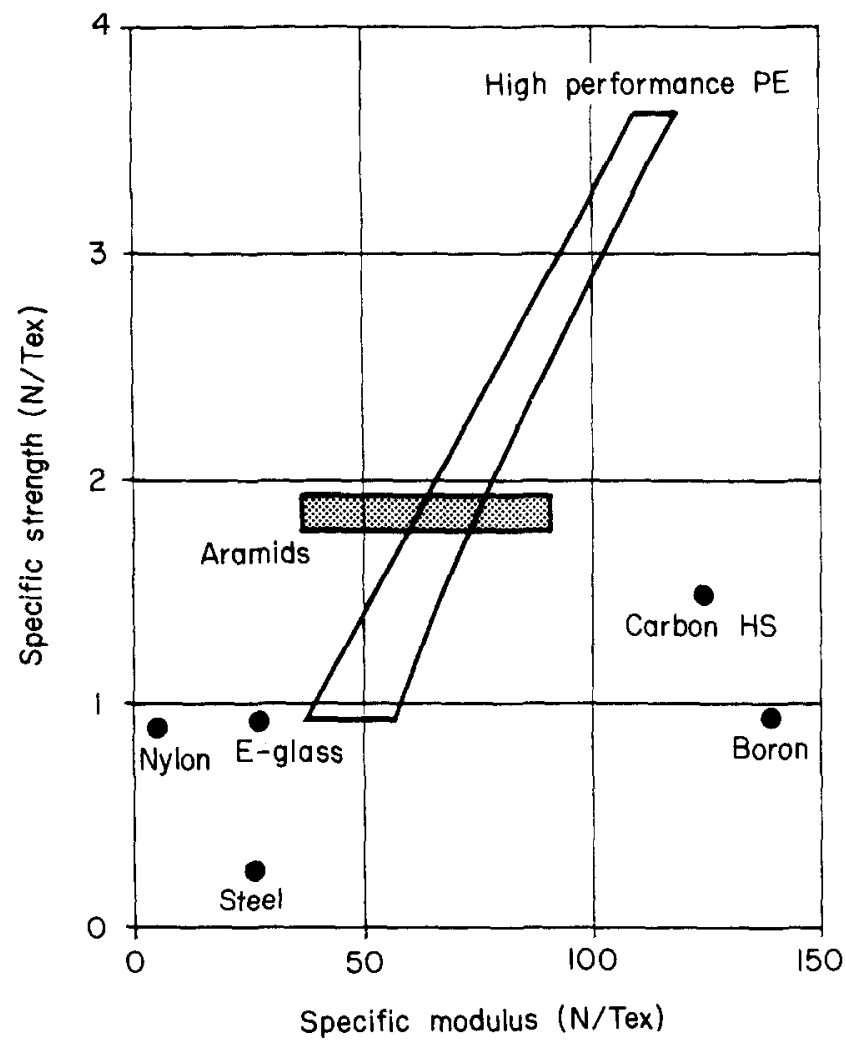

Figure 9 Properties of HP-PE fibres in comparison with other fibres 


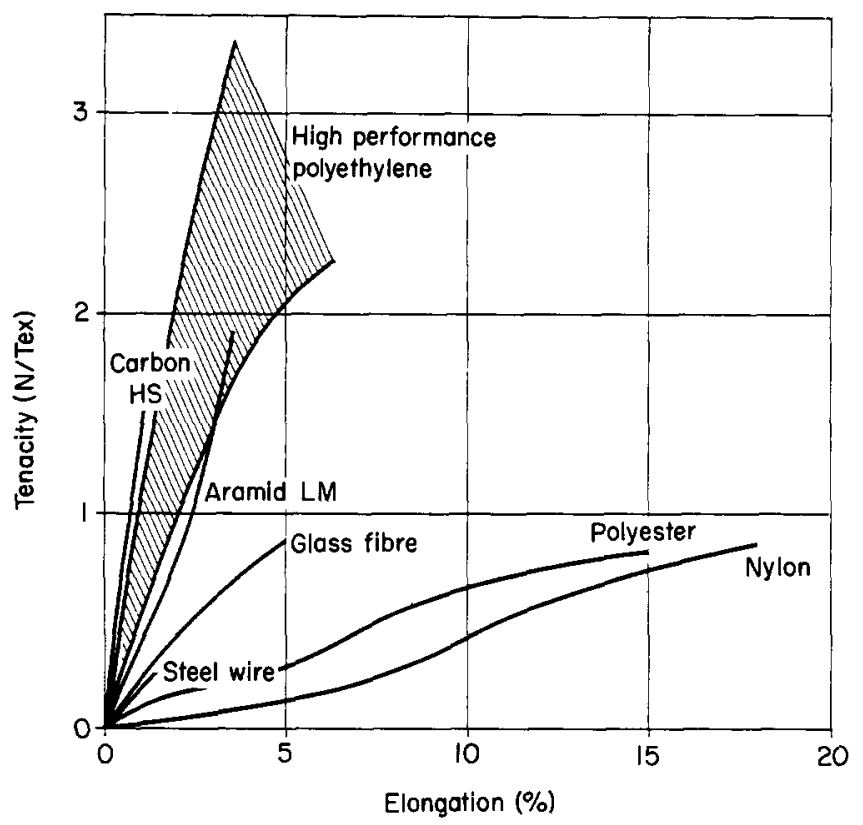

Figure 10 Stress-strain behaviour of HP-PE fibres compared to other fibres

Table 4 Modulus and work-to-break for high-performance fibres

\begin{tabular}{lrcc}
\hline Material & & $\begin{array}{l}\text { Young's modulus } \\
(\mathbf{N} / \text { tex })\end{array}$ & $\begin{array}{c}\text { Work to break } \\
(\mathrm{N} . \mathrm{m} / \mathrm{tex}) \times 10^{3}\end{array}$ \\
\hline Carbon & HS & 125 & $1-2$ \\
Aramid & HM & 80 & $2.5-3.0$ \\
Aramid & LM & 40 & $3.5-4.0$ \\
Polyethylene & 50 & $11-13$ \\
Polyethylene & 80 & $8-10$ \\
Polyethylene & 100 & $8-9$ \\
Polyethylene & 130 & $\approx 8$
\end{tabular}

a Calculated by integration of the stress-strain curve

impact resistance is needed, such as ballistic applications $^{52}$.

A convincing demonstration that HP-PE fibres are clearly different in properties (not only strength and modulus) compared with (isotropic) polyethylene is the possibility to produce thermoplastic composites of the type PE/PE consisting of HP-PE fibres embedded in a polyethylene matrix ${ }^{53}$. This is possible because the melting temperature of the HP-PE fibres is higher than those of isotropic polyethylenes and moreover depends on the constraints imposed on the fibre during melting. Figure 11 demonstrates the melting behaviour of HP-PE fibres in comparison with the starting material. At the standard heating rate adopted the chopped fibres show one major peak at $144^{\circ} \mathrm{C}$ whereas the fibres embedded in an epoxy matrix melt at $\approx 155^{\circ} \mathrm{C}$. The latter temperature has been associated with a solid-solid transition, orthorhombic to hexagonal ${ }^{29}$. Depending on sample weight, fibre length, kinks, knots etc, a combination of the two melting peaks as shown in Figure 11 can be observed or even higher melting peaks $\left(>160^{\circ} \mathrm{C}\right)$ as a result of superheating at high scan speeds.

\section{BIAXIAL DRAWING OF POLYPROPYLENE BLENDS}

\section{Barrier properties of polymers}

The main application area of synthetic polymers is packaging, ranging from films, tubes to containers. The advantages of synthetic polymers in comparison with the classical inorganic materials metals and glass, are respectively light weight and impact resistance. However for numerous applications the permeability of many polymers to gases and liquids is far too high to be competitive with and to substitute for glass and metals. The permeability relates to the rate of transmission of a permeant through a barrier. Different units and various definitions are used in literature.

The permeability coefficient $P$ may best be defined as ${ }^{54}$ :

$P=$ (amount of permeant)(film thickness)/(area)(time) (pressure-drop across film).

The permeability coefficient $P$ is often expressed as the product of a diffusion $(D)$ and solubility coefficient $(S)$ for the permeant, $P=D . S$, suggesting a simple process of consecutive dissolution and diffusion of a permeant through a (flawless) film. In actual polymeric systems, sorption and transport phenomena can be very complex, notably in glassy and semi-crystalline polymers as discussed in ref. 55 . Table 5 shows the relative permeability coefficients of well-known polymers for $\mathrm{O}_{2}$ and $\mathrm{CO}_{2}$ at room temperature, indicating a 50000 fold difference*.

The chemical structure is usually considered to be the

* Table 5 shows averaged literature data and is only meant to indicate the large difference between various polymers.

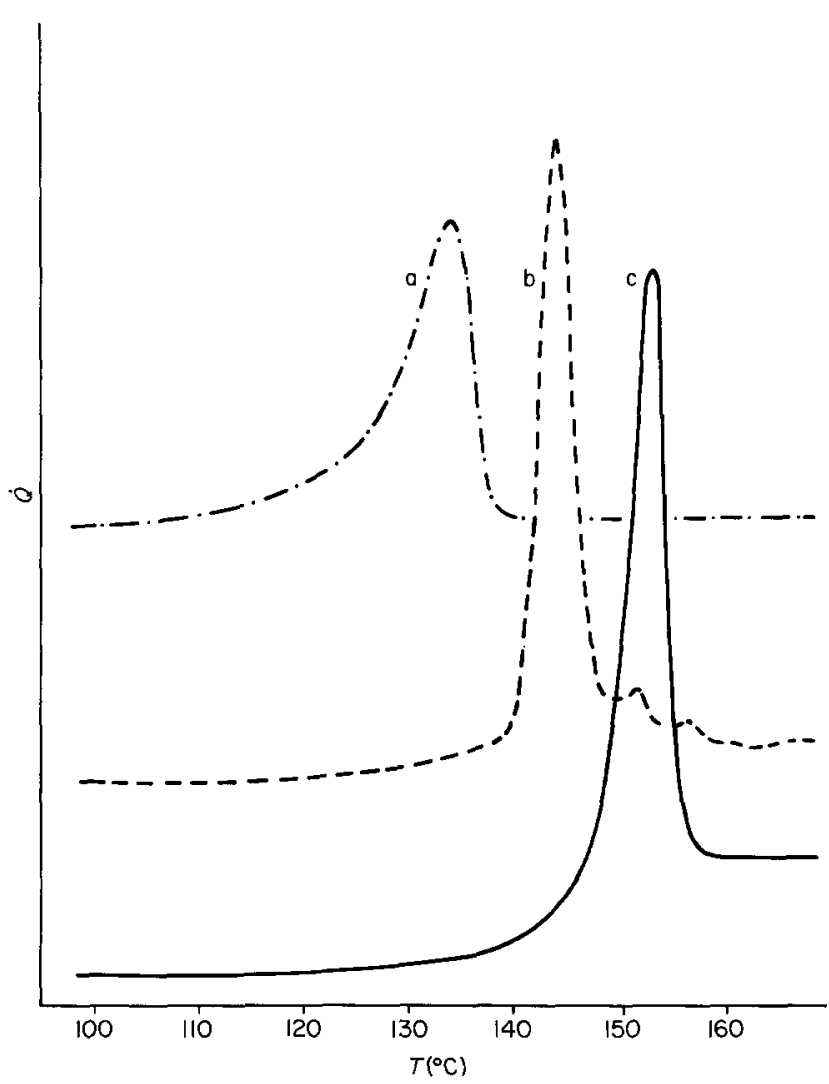

Figure 11 Melting behaviour of HP-PE fibres in comparison with isotropic PE (a) melt-crystallized isotropic UHMW-PE; (b) chopped HP-PE fibre (2 mm length); and (c) HP-PE fibres embedded in epoxy matrix 
Table 5 Relative permeability $(\mathrm{P})$ of polymers $\left(23^{\circ} \mathrm{C}\right)$

\begin{tabular}{lcc}
\hline & $P\left(\mathrm{O}_{2}\right)$ & $P\left(\mathrm{CO}_{2}\right)$ \\
\hline Polyethylene (low-density) & 20 & 100 \\
Polyethylene (high-density) & 5 & 30 \\
Polypropylene & 3 & 15 \\
Poly(vinyl chloride) & 0.3 & 1 \\
Polyester (PETP) & 0.1 & 0.5 \\
Polyamides (Nylon-6) - - - - - - -1 & 0.7 \\
Polyacrylonitrile (PAN) & 0.01 & 0.04 \\
PAN-copolymer (Barex) & 0.03 & 0.13 \\
Poly(vinylidene chloride)-copolymer & 0.02 & 0.07 \\
Poly(vinyl alcohol) (0\% R.H.) & 0.0004 & 0.002 \\
\hline
\end{tabular}

predominant factor governing the magnitude of the permeability coefficient but this is not necessarily true. For example polyethylene is relatively permeable for gases such as $\mathrm{O}_{2}$ and $\mathrm{CO}_{2}$. Since diffusion through crystallites can be neglected, the amorphous zones in polyethylene are responsible for sorption and transport.

By uniaxial drawing of linear polyethylene (based on Ward's optimized drawing method) oriented films can be produced possessing a 350-times lower permeability in comparison with isotropic polyethylene ${ }^{56}$. This demonstrates that a physical operation can change a polymer possessing poor barrier properties in the isotropic state into a high-barrier product. However conversion of uniaxially drawn films into three-dimensional structures, possessing related barrier properties, is technologically a rather complex process which is not currently used. Unfortunately, the spectacular decrease in permeability as obtained on uniaxial drawing is not achieved in biaxial drawing or multi-axial drawing.

Biaxial drawing of films (polypropylene) or multi-axial deformation of injection-moulded preforms (polyester bottles) is an important operation to improve the mechanical and optical properties. It is performed in a temperature range close to but below the melting point, in case of semi-crystalline polymers, or just above the glass transition temperature in case of amorphous systems. Despite the fact that permanent orientation is induced in these drawing modes, the decrease in permeability is rather limited, usually to a factor of 2 to 3 . This is partly related to the fact that biaxial drawing is not 'self-healing' with respect to the presence of microscopic defects in the isotropic starting sample, in contrast to uniaxial drawing. Therefore no high-barrier products based on the polyolefins PE and PP are currently produced but the experimental fact that low permeability can be obtained, provided that a high degree of crystallinity and proper molecular orientation are induced (as shown in ref. 56), will stimulate future research in this area.

The need to develop high-barrier systems based on polyolefins would not exist if polymers combining excellent barrier properties with good processability, mechanical performance and in particular non-toxicity were available. The last requirement is essential in case of contact with food. Polymers such as PVC, polyester and the polyamides are used for barrier applications but can not be considered as real barrier systems (restricted 'shelf life').

Table 5 shows, below the dotted line, some examples of intrinsically high-barrier polymers such as the homopolymers PAN, PVDC and PVAL, the latter at low relative humidities only. They all have the major disadvantage of not being processable as thermoplastic materials. This problem can be and has been solved, for instance as shown by the development of acrylonitrilemethacrylate copolymers (Barex).

With PAN-copolymers, however, serious difficulties have been encountered with respect to residual acrylonitrile monomer ${ }^{57}$. The presence of residual carcinogenic monomers immediately indicates the problem of designing and developing new intrinsic barrier polymers or copolymers based on new chemistry, i.e., 'speciality polymers', since long-term effects are unknown and may present a high risk. An interesting group of copolymers in this respect are the ethylene-vinylalcohol copolymers. Poly(vinylalcohol), a commodity polymer (at least in Japan), is non-toxic and possesses excellent barrier properties at low relative humidities. However, this polymer is hygroscopic and will lose its barrier properties with increasing relative humidity. Introduction of ethylene units in the chain will reduce the hydrophilic character and, equally important, the copolymers become thermoplastic, extrudable materials.

With increasing amounts of ethylene in the copolymer the resistance to moisture will increase but the barrier properties decrease accordingly, see below. Ethylenevinylalcohol copolymers are commercially available with ethylene contents of $\approx 30-40 \mathrm{~mol}_{\%}^{\circ}$, the so-called EVAL's ${ }^{58}$. These copolymers have to be protected from environments with relative high humidity as encountered in packaging of liquids etc. One way is to laminate these copolymers with outside layers of polyolefins such as PE or PP through co-extrusion ${ }^{59}$. Alternatively one can make blends of EVAL copolymers and polyolefins as discussed below in which the hydrophobic polyolefin matrix protects the EVAL phase.

\section{Barrier properties of incompatible blends}

Miscibility of polymers is the exception rather than the rule and, in particular, if polar polymers such as PVAL or its copolymers are mixed with polyolefins no homogeneous blends are obtained. EVAL can be dispersed in a polyolefin matrix with a proper mixing device and the resulting particle size will depend on machinery, volume fraction and viscosities of the constituents and the amount and type of compatibilizers used ${ }^{60}$.

If particles possessing barrier properties are present in a blend the permeability of the system will decrease but the effect is rather small ${ }^{61}$, at least at lower volume fractions (wbich are necessary to avoid complete deterioration of the mechanical and optical properties).

A much better situation is obtained, at least with respect to barrier properties, when processing conditions are chosen which promote deformation and elongation of the dispersed phase, preferably into two-dimensional thin layers. This has been achieved in the case of polyethylene/EVAL-blends by extrusion of the mixture under specific conditions to obtain a moulded structure consisting of thin overlapping layers of EVAL in a polyethylene matrix $^{62}$

Along similar lines a new barrier resin SELAR was recently announced by DuPont ${ }^{63}$ which is based on a mixture of polyethylene/polyamide and processing conditions which promote the formation of substantially twodimensional, parallel and overlapping layers of the polyamide in polyethylene. As shown in Table 5, polyamides 
Table 6 Properties of polyolefin/EVAL-blends ( $25 \mu \mathrm{m}$ films)

\begin{tabular}{|c|c|c|c|c|c|c|}
\hline & Blend/polymer & Draw ratio & $\begin{array}{l}\text { Gloss } \\
\text { ASTM-D2457 }\end{array}$ & $\begin{array}{l}\text { Opacity } \\
\text { ASTM-D1003 }\end{array}$ & $\begin{array}{l}\text { Impact } \\
\left(\mathrm{kJ} \mathrm{m}^{-1}\right)\end{array}$ & $\begin{array}{l}P\left(\mathrm{CO}_{2}\right)^{23(} \mathrm{C} \\
\left(\mathrm{cm}^{3} . \mathrm{cm} / \mathrm{cm}^{2} .24 \mathrm{~h} \cdot \mathrm{bar}\right)\end{array}$ \\
\hline a) & Polyethylene (LDPE) & & 55 & 10 & 35 & 100 \\
\hline b) & LDPE/EVAL( $30 \%-E), 85 / 15$ & & 8 & 50 & 7 & 1 \\
\hline c) & LDPE/EVAL $(30 \%-E), 70 / 30$ & & 5 & 90 & 0.5 & 0.2 \\
\hline d) & Polypropylene (PP) & $5 \times 5$ & 90 & 1 & 180 & 15 \\
\hline e) & PP/EVAL ( $30 \%-$-E), $75 / 25$ & $5 \times 5$ & 10 & 95 & 100 & 10 \\
\hline f) & PP/EVAL $(40 \%-$-E), $75 / 25$ & $5 \times 5$ & 85 & 2 & 150 & 0.15 \\
\hline
\end{tabular}

are medium-barrier polymers for $\mathrm{O}_{2}$ and $\mathrm{CO}_{2}$ but show a much better resistance to hydrocarbons in comparison with polyolefins and therefore these blends could be processed via single step blow moulding to produce, for instance, petrol tanks.

In general it is extremely difficult to obtain products based on incompatible blends which combine excellent barrier properties with good mechanical performance and optical properties (essential for films). The main difficulty is to match the drawing characteristics of the constituents during processing or in a later drawing-step. Table 6, for example, shows the results obtained for blown films based on polyethylene/EVAL blends. In this case a mixture of low-density polyethylene and EVAL (ECF-Kuraray) was extruded together with $5 \%$ of a compatibilizer (Admer LF-500, Mitsui) and processed into a balanced tubular film with blow-up and draw ratios of $4: 4$ and a film thickness of $\approx 25 \mu \mathrm{m}$.

There is a strong decrease in permeability due to a favourable orientation of the dispersed EVAL copolymer induced during stretching in the melt, but both the optical and mechanical properties fall below any acceptable levels, as is often encountered with incompatible polymer blends. In the case of polyethylene/EVAL blends no major improvements with respect to mechanical and optical properties could be obtained, in contrast to polypropylene/EVAL blends.

\section{PP/EVAL blends}

Biaxial drawing of polypropylene (homopolymer) is an established technique to improve optical and mechanical properties. Drawing is performed in a temperature range close to but below the melting point $\left(\approx 165^{\circ} \mathrm{C}\right.$ ) to achieve a high degree of orientation (compare uniaxial drawing of polyethylene). If a PP/EVAL-blend is extruded and subsequently drawn biaxially, the results are poor, see Table 6, $\mathrm{d}$ and $\mathrm{e}$. This is to be expected since at the drawing temperature the continuous PP matrix can be easily deformed but the dispersed EVAL phase resists deformation since its melting point is usually above the melting point of PP.

In the case of EVAL copolymers the dependence of the melting point on the ethylene content is quite exceptional. EVAL copolymers are derived from the parent EVA copolymers through complete saponification (in fact VAE copolymers in view of the minor ethylene content). EVA copolymers can be considered to be statistical copolymers and one expects that the presence of ethylene units, randomly distributed along the chain, will decrease the melting point drastically as found in related copolymers such as randomly re-acetylated poly(vinyl alcohol), stu-

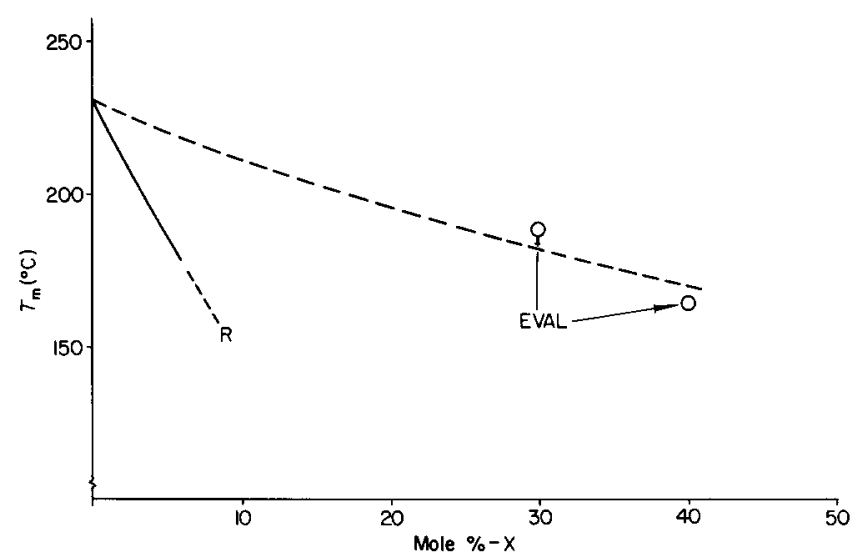

Figure 12 Melting behaviour of EVAL-copolymers compared to reacetylated PVAL copolymers (R)

died extensively by Tubbs ${ }^{64}$. Figure 12 shows the actual melting behaviour of EVAL copolymers in comparison with related statistical copolymers obtained through reacetylation of poly(vinylalcohol). The data are taken from ref. 64 and indicated by curve $\mathrm{R}$ in Figure 12 .

Following Tubbs' analysis, the average sequence length can be calculated of the 'vinyl alcohol' units in the EVAL copolymers, adopting the melting-point-depression relation of Flory:

$$
\Delta\left(T_{\mathrm{m}}\right)^{-1}=-(R / \Delta H) \ln \left(p_{j}\right)
$$

in equation (5), $\left.\Delta\left(T_{\mathrm{m}}\right)^{-1}=\left(T_{\mathrm{m}}\right)^{-1}-\left(T_{\mathrm{m}}\right)^{0}\right)^{-1}$ in which $T_{\mathrm{m}}$ is the copolymer melting point and $T_{\mathrm{m}}{ }^{0}$ the equilibrium melting point of the homopolymer, i.e., poly(vinylalcohol), $R$ is the gas constant, $\Delta H$ the heat of fusion as derived from the randomly re-acetylated samples and $p_{j}$ is the probability that monomer unit $j$ is followed by the same monomer $j$ (for statistical copolymers $p=X=$ mole fraction $j$ ).

Based on this simple analysis the average sequence length of 'vinyl alcohol' in the EVAL copolymers is more than 10 monomer units whereas from n.m.r. and copolymer kinetics of EVA copolymers it is known that these EVAL copolymers should be considered to be statistical copolymers $^{65}$. Although the authors are aware of the conditions under which equation (5) is applicable, i.e., equilibrium crystallization and melting, this simple analysis shows that the melting/crystallization behaviour of EVAL copolymers is unique, indicative of cocrystallization of ethylene and 'vinyl alcohol' units.

As a consequence of co-crystallization, ethylene units in the EVAL copolymer can be accommodated in the crystal lattice and therefore the barrier properties will remain at a high level, even up to $40-50 \mathrm{~mol} \%$ of ethylene units. For 


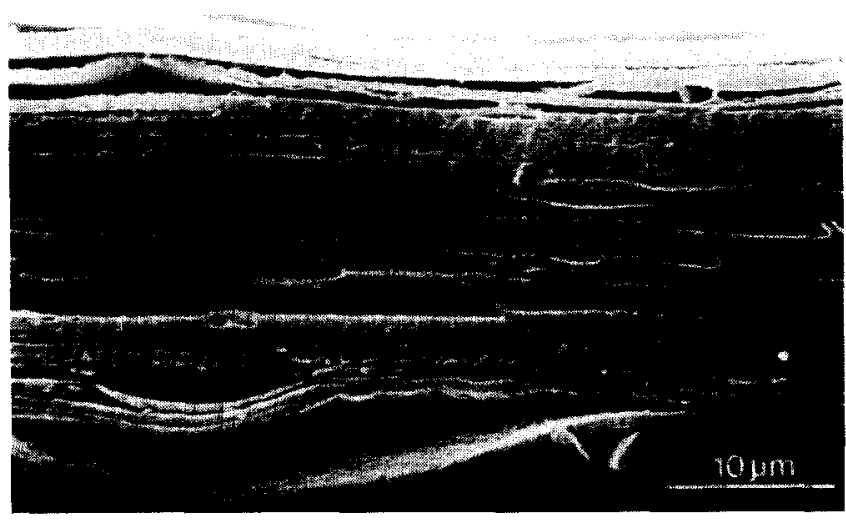

Figure 13 Scanning electron micrograph of cross-section PP/EVAL film

example, with reference to Table 5, EVAL copolymers with 30 and $40 \mathrm{~mol}^{\circ} /$ ethylene, respectively, have a relative permeability of 0.02 and 0.05 for $\mathrm{CO}_{2}$. This implies that the melting point can be adjusted within a relatively large range without losing barrier properties to a large extent. If one chooses EVAL types with $T_{\mathrm{m}}$ below the melting point of polypropylene then, on drawing, a situation is encountered in which the dispersed EVAL phase is molten and the PP matrix is semi-solid. During drawing the molten EVAL particles do not resist deformation and a favourable situation is attained, resulting in drawn structures in which finely dispersed, elongated and thin barrier layers are present in a polypropylene matrix ${ }^{66}$.

Drawn films can be obtained combining barrier properties with acceptable mechanical and optical performance as shown in Table $6 f$, obtained by biaxial drawing of PP/EVAL sheets at $162^{\circ} \mathrm{C}$. The mixture consisted of $70 \% \mathrm{PP}$ homopolymer; $25 \%$ EVAL copolymer with $43 \mathrm{~mol}^{\circ} \%$ ethylene $\left(T_{\mathrm{m}}=158 \mathrm{C}\right)$ and $5 \%$ compatibilizer Admer QF-500 (Mitsui). Figure 13 reveals the presence of thin, overlapping EVAL layers in the drawn films.

\section{CONCLUSIONS}

It was shown that optimized drawing processes dramatically improved the properties of commodity (co)polymers and their blends leading to strongly enhanced mechanical, barrier and related properties beyond previously envisaged limits. The first example demonstrates how in a time span of $\approx 15$ years ultra-stiff structures could be made based on an intrinsically flexible polymer such as polyethylene through a simple physical operation, namely uniaxial drawing. This achievement could be realized after recognizing the prime factors controlling drawability. The second example shows that intractable systems such as incompatible blends can be processed into useful products by matching their physical properties. The examples given are not exceptions but rather indications to new routes as demonstrated by recent patent applications such as the production of strong/stiff poly(vinylalcohol) fibres via a gelspinning route ${ }^{67}$ and optimized post-drawing of polyamide-fibres to increase the tensile strength beyond $1 \mathrm{GPa}^{68}$. Apart from fibres or films, processes are under development to obtain threedimensional structures such as tubes and profiles possessing superior mechanical properties, for example diedrawing of polyethylene ${ }^{69}$. In the near future new developments are to be expected based on utilization of the intrinsic properties of commodity polymers.

\section{ACKNOWLEDGEMENTS}

The authors wish to thank their former colleague Dr Paul Smith (DuPont, experimental station) for stimulating discussions. We acknowledge the help of Dr Meyer and $\mathrm{Mr}$ Bastiaansen in preparing the manuscript.

\section{REFERENCE}

Kunststoffe 1983, 73, 604

Unger, L. Long Range Planning 1983, 16(4), 12

Kunststoff Information, 1984, 686, 5

Batelle/Columbus - Innovative Materials Multiclient-study Chemisch Magazine (K.N.C.V.), 1984, Feb. Ed., 72

Mark, H. F. 'Polymer Science and Materials' (Eds. H. F. Mark and A. V. Tobolsky), Wiley Interscience, NY, 1971, p. 236

Boudreaux, D. S. J. Polym. Sci., Phys. E. 1973, 11, 1285

Carothers, W. and Hill, J. W. J. Am. Chem. Soc. 1932, 54, 1586

Schaefgen, J. R. et al. 'Ultra-High Modulus Polymers' (Eds. A Ciferri and I. M. Ward), Appl. Sci. Publ., London, 1979, Ch. 6

10 Andrews, J. M. and Ward, I. M. J. Mater. Sci. 1970, 5, 411

11 Reference 9, Chapter 1

12 Capaccio, G. and Ward, I. M. Polymer 1975, 16, 239

13 Wu, W. L. and Black, W. B. US Pat. $4228118(1980)$

14 European Chem. New's 1984, 43, 22

15 Perkins, W. G., Capiati, N. J. and Porter, R. S. Polym. Eng. Sci. $1976,16,3$

16 Capaccio, G., Compton, T. A. and Ward, I. M. J. Polym. Sci., Polym. Phys. Edn. 1976, 14, 1641

17 Faraday Discussions 1979, 68

18 Flory, P. J. 'Statistical Mechanics of Chain Molecules', John Wiley and Sons, 1969

19 Lieser, G., Fischer, E. W. and Ibel, K. Polym. Letts. 1975, 13, 19

20 Graessley, W. W. Polymer 1980, 21, 258

21 Petrie, C. J. S. 'Elongational Flows', Pitman, London, 1979, Ch. 4

22 Mackley, M. R. and Sapsford, G. S. 'Developments in Oriented Polymers' (Ed. I. M. Ward), Appl. Sci. Pub., London, 1982

23 Mackley, M. R, and Keller, A. Phil. Trans. Roy. Soc. 1975, A278, 29

24 Pennings, A. J., van der Mark, J. M. A. A. and Booy, H. C. Colloid Polym. Sci. 1970, 236, 99

25 Keller, A. and Barham, P. J. Plastics Rubber Int. 1981, 6, 19

26 Barham, P. J. and Keller, A. 'High Strength Polyethylene Fibres from Solution' J. Mater. Sci. to be published

27 Pennings, A. J. J. Polym. Sci. Polym. Symp. 1977, 59, 55

28 Zwijnenburg, A. and Pennings, A. J. Colloid Polym. Sci. 1975, 253, 452

29 Zwijnenburg, A. PhD Thesis, University of Groningen, Holland 1978

30 DSM/Stamicarbon, US Pat. 4137394

31 Allied Corp. European Patent Appl. 56875

32 DSM/Stamicarbon, US Pat. 4344908

33 DSM/Stamicarbon, US Pat. 4422993; 4430383; 4436689

34 Allied Corp. European Patent Appl. 64167

35 Hikmet, R. A. M. and Lemstra, P. J., to be published

36 Smith, P., Lemstra, P. J., Kalb, B. and Pennings, A. J. Polym. Bull $1979,1,733$

37 Smith, P. and Lemstra, P. J. Colloid Polym. Sci. 1980, 258, 891

38 Kalb, B. and Pennings, A. J. Polymer 1980, 21, 3

39 Lemstra, P. J. and Smith, P. Br. Polym. J. 1980, 12, 212

40 Smith, P., Lemstra, P. J. and Booy, H. C. J. Polym. Sci., Polym Phys. Edn. 1981, 19, 877

41 Statton, W. O. J. Appl. Phys. 1967, 38, 4149

42 Smith, P. Macromol. 1983, 16, 1802

43 Schreiber, H. P. Polym. Eng. Sci. 1983, 23, 422

44 Cutter, D. J., Hendra, P. and Sang, R. Ref. 17, p. 320

45 Folland, R. and Charlesby, A. Eur. Polym. J. 1979, 15, 953

46 De Gennes, P. G. 'Scaling Concept in Polymer Physics', Cornell Univ. Press, 1979, Ch. 8

47 De Gennes, P. G. J. Chem. Phys. 1971, 55, 572

48 Klein, J. and Briscoe, B. J. Proc, Ro1. Soc. London 1979, A365, 53

49 Kanamoto, T., Tsuruta, A., Tanaka, Takeda. M. and Porter, R.S Polym. J. 1983, 15, 327

50 De Gennes, P. G. Macromol. 1984, 17, 703

51 Doi, M. and Edwards, S. J. Chem. Soc. Faraday Trans, 1978, 274 1789

52 Allied Corp. US Pat. 4403012 


\section{Commodity polymers as speciality products: P. J. Lemstra and R. Kirschbaum}

53 Allied Corp. European Patent Appl. 89.502; 110.021

54 'Polymer Handbook' 2nd Edition (Eds. J. Brandrup and E. H. Immergut), John Wiley and Sons, NY, 1975, Ch. III-8 Frisch, H. L. Polym. Eng. Sci. 1980, 20, 2

Metal Box, European Patent Appl. 639

F. D. A. Docket $6 \mathrm{~N}-0070,1977$

Chem. Econ. Eng. Rev. 1977, 9. 32

Hensen, F., Hessenbruch, R. and Bongaerts, H. Kunststoffe 1981, 71, 530

60 Avgeropoulos, G. N., Weisert, F. C., Biddison, P. H. and Böhm, G. G. A. Rubber Chem. Technol. 1976, 49, 93
61 Crank, J. 'The Mathematics of Diffusion', 2nd Edn., Arrowsmith Ltd., Bristol, 1979, Ch. 12

62 Toyo Seikan Ltd. US Pat. 3847728

63 E. I. DuPont de Nemours and Comp. European Patent Appl. 90554

64 Tubbs, R. K. J. Polym. Sci., Polym. Chem. Edn. 1966, 4, 623

65 Schrijver, J. PhD Thesis, Eindhoven University, 1981

66 DSM/Stamicarbon NL Pat. 8003192

67 Allied Corp. US Pat. 4413110

68 Toyo Boseki European Patent Appl. 74327; 85972

69 National Research Dev. Corp. European Patent Appl. 38798 